Research Paper

\title{
Borrelia burgdorferi basic membrane protein A stimulates murine macrophage to secrete specific chemokines
}

\author{
Yun Peng ${ }^{1^{*}}$, Zhang Liang $3,4^{*}$, Aihua Liu ${ }^{2,3,4,5,6}$, Erhua Li ${ }^{1}$, Xiting Dai ${ }^{1}$, Ruolan Bai ${ }^{2}$, Zhenhua Ji ${ }^{1}$, Miaomiao \\ Jian², Mingbiao Ma1, Lvyan Tao ${ }^{2}$, Fukai Bao ${ }^{1,2,4,5,6}{ }^{凶}$,Feng Wang ${ }^{1}$, YunFeng Bi ${ }^{1}$, Zhe Ding ${ }^{1}$, Abi \\ Manzama-Esso ${ }^{1}$ \\ 1. Department of Microbiology and Immunology, Kunming Medical University, Kunming 650500, China, \\ 2. Department of Biochemistry and Molecular Biology, Kunming Medical University, Kunming 650500, China, \\ 3. Yunnan Province Key Laboratory for Tropical Infectious Diseases in Universities, Kunming Medical University, Kunming 650500, China, \\ 4. The Institute for Tropical Medicine, Kunming Medical University, Kunming 650500, China, \\ 5. Yunnan Demonstration Base of International Science and Technology Cooperation for Tropical Diseases, Kunming 650500, China, \\ 6. Yunnan Province Integrative Innovation Center for Public Health, Diseases Prevention and Control, Kunming Medical University, Kunming 650500, China. \\ *These authors contributed equally to the study. \\ $\triangle$ Corresponding authors: E-mail: AihuaLiu, liuaihua@kmmu.edu.cn; FukaiBao, baofukai@kmmu.edu.cn; Tel: 86-13888369882; Fax: 86-871-65922857; Address: \\ Kunming Medical University, 1186 Chunrongxi road, Chenggong District, Kunming 650500, Yunnan, P. R. of China.
}

(C) Ivyspring International Publisher. This is an open access article distributed under the terms of the Creative Commons Attribution (CC BY-NC) license (https://creativecommons.org/licenses/by-nc/4.0/). See http://ivyspring.com/terms for full terms and conditions.

Received: 2018.04.13; Accepted: 2018.06.08; Published: 2018.10.02

\begin{abstract}
In this study, we investigated the mechanisms that lead to the production of proinflammatory mediators by the murine macrophage cell line, RAW264.7, when these cells are exposed in vitro to recombinant Borrelia burgdorferi basic membrane protein $A(r B m p A)$. Using antibody protein microarray technology with high-throughput detection ability for detecting 25 chemokines in culture supernatant the RAW264.7 cell culture supernatants at 12 and 24 h post-stimulation with rBmpA, we identified two chemokines, a monocyte chemoattractant protein-5 (MCP-5/CCL12) and a macrophage inflammatory protein-2 (MIP-2/CXCL2), both of which increased significantly after stimulation. We then chose these two chemokines for further study. Enzyme-linked immunosorbent assay and real-time polymerase chain reaction revealed that with the increase of $\mathrm{rBmpA}$ concentration, MCP-5/CCL12 and MIP-2/CXCL2 showed concentration-dependent increases ( $\mathrm{P}$ $<0.01$ ). Our results indicate that the $r B m p A$ could stimulate the secretion of several specific chemokines and induce Lyme arthritis.
\end{abstract}

Key words: Borrelia burgdorferi, basic membrane protein A (rBmpA), murine macrophage cell line, RAW264.7, chemokine, Lyme arthritis

\section{Introduction}

Lyme disease is caused by the spirochetal bacteria, Borrelia burgdorferi, and is transmitted by ticks of the genus Ixodes [1]. Invasion of the mammalian host by B. burgdorferi results in the release of inflammatory mediators and the influx of inflammatory cells in multiple organs such as the skin, heart, joints, and central and peripheral nervous systems [2-5]. Arthritis is one of its most important features and also is the most distinguishing feature of late-stage Lyme disease $[5,6]$. The mechanism by which $B$. burgdorferi induces joint damage is only partially understood. Considering Lyme arthritis is known to progress relatively slowly $[7,8]$, it is thought that inflammation, induced either by the spirochete or by the spirochetal antigens left in tissues after bacterial demise, plays a major role in disease pathogenesis [9].

$\mathrm{BmpA}$ is a member of the paralogous $\mathrm{Bmp}$ protein family, which is encoded by the tandemly arrayed bmp genes on the linear B. burgdorferi chromosome and located in the outer membrane surface of spirochetes as membrane lipoproteins [10]. It is also highly immunogenic in human beings and animals and is one of the antigens used in serodiagnostic tests for Lyme disease [11]. Our previous study found that the B.burgdorferi basic membrane protein A (BmpA) is involved in the genesis of Lyme arthritis [11]. The BmpA gene of 
Lyme-causing spirochetes was preferentially up-regulated in mouse joints compared with other organs, and B. burgdorferi lacking BmpA failed to induce arthritis [11]. Research on BmpA may help promote understanding of $B$. burgdorferi pathogenesis and provide an important basis for diagnosis and treatment of Lyme disease.

Lyme disease occurs with both the innate immune and the adaptive immune responses [12]. The knee joints suffer more often, and the pathological manifestations of the lesion were monocytic infiltration, synovial hypertrophy, and vascular dilation [13]. Chemokines play an important role in innate and adaptive immunities via mediation of inflammatory cell chemotaxis and the release of inflammatory mediators; they have a close relationship with acute and chronic inflammatory diseases [14]. In recent years, with the thorough study of Lyme disease and Lyme arthritis, results have shown that chemokines could be key mediators in Lyme disease. When comparing chemokine secretion levels in arthritis-susceptible mice $(\mathrm{C} 3 \mathrm{H}$ mice) and tolerant mice (C56BL mice) after spirochete ankle joint inoculation, the results showed that the neutrophil chemokine KC (CXCL1) and monocyte chemotactic factor MCP-I (CCL2) were overexpressed in the $\mathrm{C} 3 \mathrm{H}$ mice infected with $B$. burgdorferi. This caused monocyte and neutrophil invasion of the joint tissue, which led to arthritis [15]. Other animal model studies also showed that $\mathrm{C} 3 \mathrm{H}$ mice deficient in TLR2 infected with B. burgdorferi, the chemokines CXCL9 and 10 are expressed in large amounts in mouse joints, thus attracting mononuclear and other inflammatory cells to infiltrate to the joints and resulting in the occurrence of Lyme arthritis [16]. In addition, in a study on chemokine levels of synovial fluid samples in 49 Lyme arthritis patients, the authors found that 33 antibiotic-resistant patients had much higher chemokine levels in their synovial fluid samples [17]. Researchers also studied proliferation of peripheral blood mononuclear cells (PBMC) and $\mathrm{CD}_{14}^{+}$ monocytes/macrophages in patients with Lyme arthritis. The results showed that B. burgdorferistimulated cells could induce the production of chemokines CCL2 and 4 and CXCL9 and 10, which was statistically significantly different compared with unstimulated cells. The results also indicated that $B$. burgdorferi could directly stimulate monocytemacrophages to secrete a large number of chemokines, which revealed that inherent immune responses play an important role in early and late Lyme disease. On the other hand, B. burgdorferi could stimulate other cells (such as natural killer [NK] cells) to produce interferon- $\gamma$ and indirectly induce T cells to gather in the joint tissue, which then initiates an adaptive immune response in the body [18]. In summary, chemokines are closely related to the occurrence of Lyme arthritis, which mediates the innate immune response and participates in adaptive immune responses. This study aimed to differentially sort out key expressed chemokines after murine macrophages were stimulated with $\mathrm{rBmpA}$ and to explore the potential role of $B$. burgdorferi dominant proteins during Lyme arthritis pathogenesis.

\section{Materials and methods}

\section{rBmpA Preparation}

The recombinant BmpA (rBmpA) was produced in $E$. coli using the bacterial expression vector pGEX-6P1 (GE, USA) and the following primers with EcoR I and Xho I restriction sites (5-3)ACG AAT TCA TGA ATA AAA TAT TGT TGT TGA, AGC TCG TAA ATA AAT TCT TTA AGA AA [19]. Expression, purification, and enzymatic cleavage of glutathione transferase fusion protein and rBmpA harvest were carried out as previously described [20]. Lipopolysaccharide (LPS) and phorbol-12-myristate-13-acetate were purchased from Sigma- Aldrich (USA), and ionomycin was purchased from Apollo (USA).

\section{Cell cultures}

The murine macrophage cell line, RAW264.7, was obtained from Kunming Institute of Zoology, Chinese Academy of Sciences (Kunming, China). Cell culture supplies were obtained from Gibco, Life Technologies (USA). The cells were maintained at 37 ${ }^{\circ} \mathrm{C}, 5 \% \mathrm{CO}_{2}$ and cultured in high-glucose Dulbecco's modified Eagle medium with $10 \%$ fetal bovine serum, $10000 \mathrm{U} / \mathrm{ml}$ penicillin, and $10 \mathrm{mg} / \mathrm{ml}$ streptomycin. For rBmpA stimulation test, RAW264.7 cells were seeded in 96-well microplates at a concentration of $8 \times 10^{4} \sim 1 \times 10^{5} / \mathrm{ml}$ and stimulated with $10 \mu \mathrm{g} / \mathrm{ml}$ $\mathrm{rBmpA}$ and $20 \mu \mathrm{g} / \mathrm{ml} \mathrm{rBmpA}$. Other cells were also maintained in the medium as blank controls and stimulated with $1 \mu \mathrm{g} / \mathrm{ml}$ LPS as positive controls. Cellular supernatants were collected 12, 24, and $48 \mathrm{~h}$ post-stimulation and stored at $-80{ }^{\circ} \mathrm{C}$ until used for antibody high-throughput microarray analysis and enzyme-linked immunosorbent assay (ELISA). Cell lysates were prepared using the RNAiso Plus reagent (Takara, Japan) and stored at $-80^{\circ} \mathrm{C}$ until used for RNA extraction.

\section{High-throughput Detection of chemokines}

Twenty-five chemokines in cell culture supernatants from RAW264.7 cells at 12 and 24 h poststimulation with rBmpA were detected by chemokine protein microarray technology (RayBiotech, Inc.) in order to sort out highly expressed chemokines. 


\section{RNA Extraction and Real-time Quantitative PCR}

mRNA expressions of MCP-5/CCL12 and MIP-2/CXCL2 were assessed by quantitative real-time PCR (qPCR). Total RNA was extracted from cells using the RNAiso Plus reagent (TaKaRa, Japan) according to the manufacturer's instructions. Prime Script RT reagent Kit with gDNA Eraser (TaKaRa, Japan) was used to synthesize cDNA according to the manufacturer's protocol. Relative gene expression levels were calculated using the comparative threshold-cycle method of quantitative PCR with data normalized to the housekeeping gene, glyceraldehyde 3-phosphate dehydrogenase (GAPDH). Specific primer sequences used to amplify murine MCP-5/ CCL12, MIP-2/CXCL2 and GAPDH consisted pf several primers: murine MCP-5 (forward: 5'-TTC CAC ACT TCT ATG CCT GC -3', reverse: 5'- CTG GCT TGT GAT TCT CCT GT $-3^{\prime}$ ), murine MIP-2 (forward: 5' - CAC TCT CAA GGG CGG TCA AA -3', reverse: 5'- GCT CCT TTC CAG GTC AGT TA -3'), murine GAPDH (forward: 5'- TCC CAG AGC TGA ACG GGA AG-3', reverse: 5'- TCA GTG GGC CCT CAG ATG C $-3^{\prime}$ ). qPCR was performed using the SYBR Premix Ex Taq (TaKaRa, Japan) according to the manufacturer's protocol. The total volume used in the PCR reaction was $20 \mu l$.

\section{ELISA}

Highly expressed MCP-5/CCL12 and MIP-2/
CXCL2 in the microarray were chosen for additional studies. The MCP-5/CCL12 and MIP-2/CXCL2 concentrations of all cell supernatant samples were measured using the ELISA method. The ELISA was performed using Mouse MCP-5 ELISA Kit Mouse MIP-2 ELISA kit (RayBiotech, Inc. Guangzhou,China) according to the manufactures' protocols.

\section{Statistical analysis}

Results were expressed as the mean \pm SEM. The significance of the difference between the mean values of the groups was evaluated by one-way analysis of variance method of square-deviation using the statistical analysis software GraphPad Prism 6.0. Differences were considered statistically significant at a value of $\mathrm{P}<0.05$.

\section{Results}

\section{Murine microarrays sorted out several highly expressed chemokines}

When compared with the blank control group, rBmpA can stimulate the mouse macrophage cell line RAW264.7 cells to secrete a variety of chemokines. LPS and 10 and $20 \mu \mathrm{g} / \mathrm{ml} \mathrm{rBmpA}$ induced higher level of 23 kinds of chemokines found in the supernatant from murine macrophages both 12 and $24 \mathrm{~h}$ post-stimulation. The secretion levels of MCP-5/CCL12 and MIP-2/CXCL2 also increased significantly. Thus, we chose MCP-5/CCL12 and MIP-2/CXCL2 for further study (Table 1).

Table 1. The results of 25 mouse chemokines detection of cell culture supernatant $(\mathrm{pg} / \mathrm{ml})$

\begin{tabular}{|c|c|c|c|c|c|c|c|c|c|}
\hline \multicolumn{2}{|c|}{ Chemokine } & \multicolumn{4}{|c|}{$12 \mathrm{~h}$ group } & \multicolumn{4}{|c|}{$24 \mathrm{~h}$ group } \\
\hline $\begin{array}{l}\text { Standard } \\
\text { name }\end{array}$ & $\begin{array}{l}\text { Former } \\
\text { Name }\end{array}$ & $\begin{array}{l}\text { Negative } \\
\text { control }\end{array}$ & LPS & $\begin{array}{l}\text { rBmpA } \\
10 \mu \mathrm{g} / \mathrm{ml}\end{array}$ & $\begin{array}{l}\text { rBmpA } \\
20 \mu \mathrm{g} / \mathrm{ml}\end{array}$ & $\begin{array}{l}\text { negative } \\
\text { control }\end{array}$ & LPS & $\begin{array}{l}\text { rBmpA } \\
10 \mu \mathrm{g} / \mathrm{ml}\end{array}$ & $\begin{array}{l}\text { rBmpA } \\
20 \mu \mathrm{g} / \mathrm{ml}\end{array}$ \\
\hline CCL1 & TCA-3 & 0.4 & 1.4 & 0.8 & 1.0 & 0.2 & 1.0 & 0.9 & 0.8 \\
\hline CCL2 & MCP-1 & 17.6 & 42.4 & 33.1 & 22.3 & 17.3 & 79.6 & 38.6 & 36.1 \\
\hline CCL3 & MIP-1 & 401.7 & 10259.6 & 5368.2 & 8071.8 & 591.5 & 8707.8 & 10058.0 & 8409.3 \\
\hline CCL5 & RANTES & 16.7 & 788.3 & 379.2 & 463.1 & 20.2 & 921.8 & 419.4 & 546.5 \\
\hline CCL9 & MIP-1 & 2176.6 & 5147.1 & 4068.9 & 4096.0 & 2091.8 & 5722.6 & 4137.5 & 4221.4 \\
\hline CCL11 & Eotaxin & 2.5 & 3.5 & 1.7 & 1.8 & 0.4 & 2.9 & 4.4 & 0.9 \\
\hline$\underline{\text { CCL12 }}$ & $\underline{\mathrm{MCP}-5}$ & $\underline{3.9}$ & $\underline{803.4}$ & $\underline{145.6}$ & $\underline{257.4}$ & $\underline{4.2}$ & $\underline{1500.9}$ & $\underline{232.4}$ & $\underline{432.4}$ \\
\hline CCL17 & TARC & 25.9 & 26.6 & 36.5 & 19.7 & 7.2 & 33.8 & 28.9 & 29.4 \\
\hline CCL19 & MIP-3 & 0.5 & 0.9 & 1.2 & 1.2 & 0.2 & 0.9 & 0.5 & 1.0 \\
\hline CCL20 & MIP-3 & 0.0 & 3.6 & 0.8 & 0.0 & 0.0 & 1.7 & 3.8 & 0.0 \\
\hline CCL21 & 6Ckine & 46.1 & 27.1 & 72.4 & 50.7 & 42.4 & 98.4 & 59.1 & 63.7 \\
\hline CCL22 & MDC & 40.2 & 339.4 & 104.6 & 129.9 & 27.3 & 500.3 & 111.4 & 96.8 \\
\hline CCL24 & Eotaxin2 & 4.0 & 10.5 & 7.2 & 5.9 & 2.1 & 5.8 & 2.1 & 7.8 \\
\hline CCL25 & TECK & 455.5 & 995.0 & 1065.4 & 301.6 & 306.0 & 918.9 & 567.9 & 608.4 \\
\hline CCL27 & CTACK & 484.1 & 3521.6 & 1318.4 & 1948.2 & 1630.9 & 2385.1 & 2328.2 & 3008.2 \\
\hline CXCL1 & $\mathrm{KC}$ & 0.0 & 0.7 & 0.0 & 0.0 & 0.0 & 0.0 & 0.0 & 0.0 \\
\hline CXCL2 & $\underline{\text { MIP-2 }}$ & $\underline{23.7}$ & $\underline{3312.3}$ & $\underline{1115.6}$ & $\underline{1374.2}$ & $\underline{23.2}$ & $\underline{3463.1}$ & $\underline{1028.0}$ & $\underline{1466.7}$ \\
\hline CXCL4 & PF4 & 0.0 & 41.3 & 6.2 & 24.4 & 8.1 & 18.0 & 44.5 & 12.4 \\
\hline CXCL5 & LIX & 5.9 & 10.9 & 8.9 & 6.8 & 0.0 & 13.5 & 7.7 & 3.0 \\
\hline CXCL9 & MIG & 55.7 & 72.2 & 43.6 & 53.0 & 26.2 & 54.1 & 105.7 & 32.2 \\
\hline CXCL11 & I-TAC & 97.3 & 80.3 & 111.5 & 80.0 & 21.5 & 113.8 & 87.3 & 65.0 \\
\hline CXCL12 & SDF-1a & 0.0 & 0.7 & 17.4 & 0.8 & 4.4 & 4.5 & 0.1 & 1.4 \\
\hline CXCL13 & BLC & 117.6 & 121.3 & 203.2 & 160.8 & 146.4 & 261.0 & 134.1 & 200.4 \\
\hline CXCL16 & CXCL16 & 2.3 & 12.7 & 4.7 & 7.4 & 3.9 & 20.8 & 6.6 & 8.7 \\
\hline CX3CL1 & Fractalkine & 75.5 & 119.4 & 76.2 & 28.6 & 55.8 & 86.3 & 66.9 & 14.8 \\
\hline
\end{tabular}




\section{RT-PCR confirmed higher expression of MCP-5/CCL1 2 and MIP-2/CXCL2}

MCP-5 (CCL12) mRNA expression levels in murine macrophages were detected in each sample. As shown in Figure 1, relative expression levels of MCP-5 (CCL12) were significantly higher in both LP S- and 10 and $20 \mu \mathrm{g} / \mathrm{ml} \mathrm{rBmpA-treated} \mathrm{cells} \mathrm{than} \mathrm{in}$ the blank control at 12 and $24 \mathrm{~h}$ post-stimulation ( $\mathrm{P}$ $<0.01$ ). The differences at the 48 -h time point did not reach significance, however, when compared to the control. rBmpA up-regulated the expression of the MCP-5 gene in mouse macrophage RAW264.7 cells at the 12 and $24 \mathrm{~h}$ time points, but after longer stimulation periods with $\mathrm{rBmpA}$, the MCP-5 gene expression level gradually decreased (Figure 1 ).

MIP-2/CXCL2 mRNA expression levels in murine macrophages were detected in each sample. MIP-2/CXCL2 relative expression levels were significantly higher in murine macrophages induced by LPS and 10 and $20 \mu \mathrm{g} / \mathrm{ml} \mathrm{rBmpA}$ than in blank

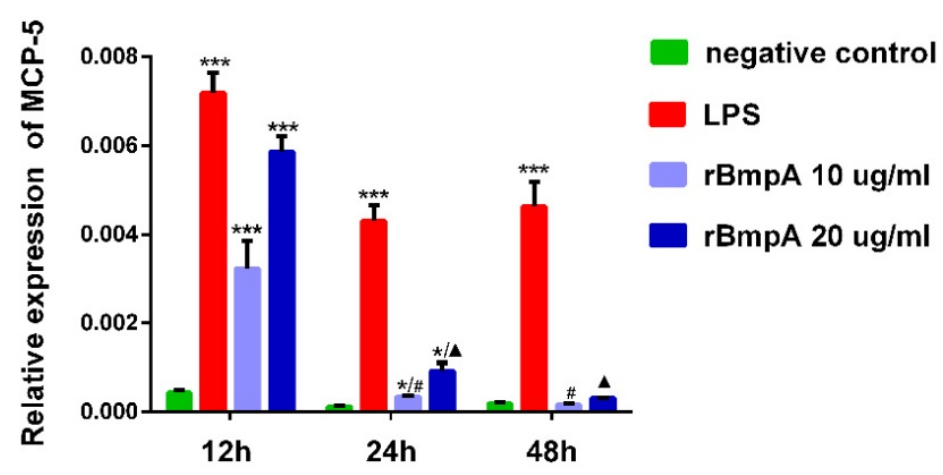

Figure 1. The relative expression of CCL12 (MCP-5) mRNA in mouse macrophage RAW 264.7. Notes: $*$ Indicates a significant difference from the negative control in the same times. * $\mathrm{P}<0.05$, ** $\mathrm{P}<0.01$, *** $\mathrm{P}<0.001$ \#Indicates a significant difference when compared with $10 \mu \mathrm{g} / \mathrm{ml} \mathrm{rBmpA}$ group at $12 \mathrm{~h}$ time point. $\# \mathrm{P}<0.05$, \# $\# \mathrm{P}<0.01$, \#\# \#P<0.001 ${ }^{\triangle}$ Indicates a significant difference when compared with $20 \mu \mathrm{g} / \mathrm{ml}$ rBmpA group at $12 \mathrm{~h}$ time point. ${ }^{\boldsymbol{\Lambda}} \mathrm{P}<0.05,{ }^{\boldsymbol{\Lambda}} \mathrm{P}<0.01,{ }^{\boldsymbol{\Lambda} \Delta}{ }^{\boldsymbol{\Delta}} \mathrm{P}<0.001$

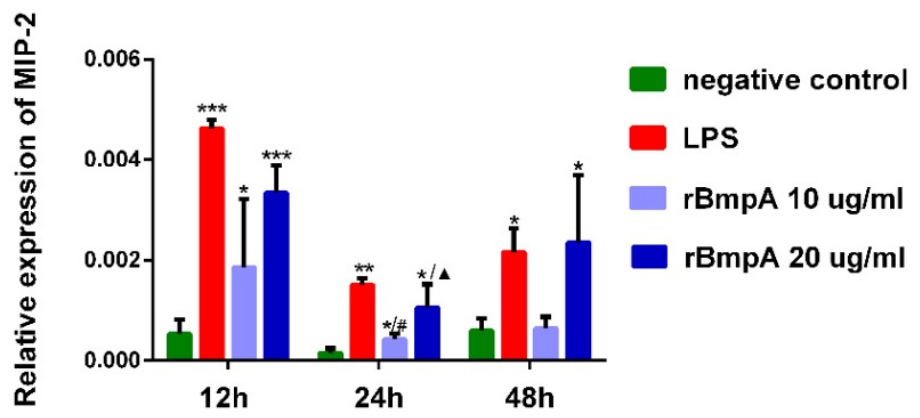

Figure 2. The relative expression of CXCL2 (MIP-2) mRNA in mouse macrophage RAW264.7 at different time points. Notes: * Indicates a significant difference from the negative control in the same times. $* \mathrm{P}<0.05$, ** $\mathrm{P}<0.01$, *** $\mathrm{P}<0.001$ \#Indicates a significant difference when compared with $10 \mu \mathrm{g} / \mathrm{ml} \mathrm{rBmpA}$ group at $12 \mathrm{~h}$ time point. \#P<0.05, \# \#P<0.01, \# \# \#P<0.001 \'Indicates a significant difference when compared with $20 \mu \mathrm{g} / \mathrm{ml} \mathrm{rBmpA}$ group at $12 \mathrm{~h}$ time point. ${ }^{\boldsymbol{\Delta}} \mathrm{P}<0.05,{ }^{\boldsymbol{\Delta}} \mathrm{P}<0.01,{ }^{\boldsymbol{\Delta} \Delta \boldsymbol{\Delta}}$ $\mathrm{P}<0.001$ controls 12,24 , and $48 \mathrm{~h}$ post-stimulation $(\mathrm{P}<0.01)$. With the exception of no significant differences between $10 \mu \mathrm{g} / \mathrm{ml} \mathrm{rBmpA}$ and controls at the $48-\mathrm{h}$ time point $(\mathrm{P}>0.05), \mathrm{rBmpA}$ up-regulated the expression level of MIP-2 gene in murine macrophage cells in a concentration-dependent manner. However, at the longer period of $\mathrm{rBmpA}$ time stimulation, the expression level of MIP-2 gene in cells decreased gradually (Figure 2).

\section{ELISA confirmed higher secretion of MCP-5/CCL 12 and MIP-2/CXCL2}

The MCP-5 (CCL12) concentrations were quantified using the ELISA at different culture time points $(12,24$, and $48 \mathrm{~h})$. Compared with the blank control group, LPS and 10 and $20 \mu \mathrm{g} / \mathrm{ml} \mathrm{rBmpA}$ induced significantly higher MCP-5 (CCL12) levels in the supernatant from murine macrophages at 12, 24, and $48 \mathrm{~h}$ post-stimulation ( $\mathrm{P}<0.01)$. MCP-5 (CCL12) concentrations after LPS treatment were $311.025 \pm 44.268,1156.345 \pm 124.827$, and 2706.576 \pm $586.054 \mathrm{pg} / \mathrm{ml}$ at 12,24 , and $48 \mathrm{~h}$, respectively. After $10 \mu \mathrm{g} / \mathrm{ml} \mathrm{rBmpA}$ treatment, MCP-5 levels were $58.660 \pm 4.569, \quad 54.556 \pm 8.426$, and $76.901 \pm 5.411 \mathrm{pg} / \mathrm{ml}$ at 12,24 , and $48 \mathrm{~h}$ post-stimulation, respectively and after $20 \mu \mathrm{g} / \mathrm{ml} \mathrm{rBmpA}$, the levels were $84.867 \pm 1.592$, $157.962 \pm 20.564$, and $168.014 \pm 22.489 \mathrm{pg} / \mathrm{ml}$ at 12 , 24 , and $48 \mathrm{~h}$ post-stimulation, respectively. With the increase in rBmpA concentrations, MCP-5 in cell culture supernatants showed a concentration-dependent increase $(p<0.01)$. The chemokine MCP-5 expression levels in RAW264.7 cells was up-regulated in a time-dependent manner with the same dose of $\mathrm{rBmpA}$, and the difference was statistically significant $(p<0.01)$. The results showed that with the increase of $\mathrm{rBmpA}$ concentration and increase in stimulation period, the amount of MCP-5 in RAW264.7 cells increased to varying levels (Figure 3).

ELISA was used to quantify MIP-2/CXCL2 concentrations at different stimulation time points $(12,24$, and $48 \mathrm{~h})$. Compared with the normal control group, LPS and 10 and $20 \mu \mathrm{g} / \mathrm{ml}$ $\mathrm{rBmpA}$ induced significantly higher MIP-2/CXCL2 levels in the supernatant from murine macrophages 12,24 , and $48 \mathrm{~h}$ post stimulation $\quad(\mathrm{P} \quad<0.01) . \quad$ MIP-2/CXCL2 concentrations after LPS treatment were $14863.7 \pm 214.531, \quad 18219.0 \pm 334.34, \quad$ and $40314.0 \pm 383.946 \mathrm{pg} / \mathrm{ml}$ at 12,24 , and $48 \mathrm{~h}$, respectively. After treatment with $10 \mu \mathrm{g} / \mathrm{ml}$ rBmpA, MIP-2/CXCL2 concentrations were $221.445 \pm 10.784, \quad 203.072 \pm 21.838, \quad$ and 
$767.365 \pm 38.37 \mathrm{pg} / \mathrm{ml}$ at 12,24 , and $48 \mathrm{~h}$ post-stimulation, respectively, and after $20 \mu \mathrm{g} / \mathrm{ml}$ rBmpA treatment, levels were 451.215 \pm 9.488 , $422.085 \pm 13.8$, and $1453.125 \pm 101.02 \mathrm{pg} / \mathrm{ml}$ at 12,24 , and $48 \mathrm{~h}$ post stimulation, respectively (Figure 4 ).

\section{Discussion}

Lyme disease is a global epidemic disease, which is widely distributed, rapidly spread, and causes a high disability rate. It has become a global health issue, which has attracted a lot of attention from the medical community. Lyme arthritis is the main form of Lyme disease, which is one of the most harmful effects of Lyme disease. Without appropriate antibiotic therapy, approximately $60 \%$ of the infected patients develop Lyme arthritis [21].

BmpA protein, as the product of B. burgdorferi gene bmpA and one of $B$. burgdorferi 's main antigens, plays a key role in Lyme arthritis [22]. In an effort to understand how BmpA stimulates murine

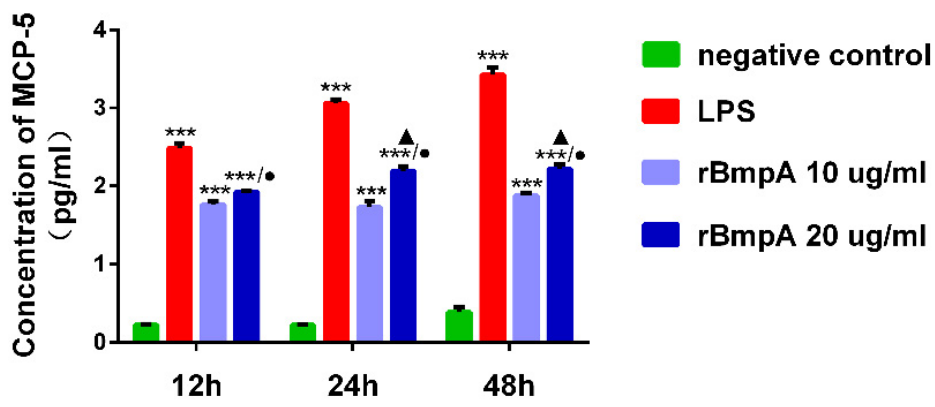

Figure 3. The concentrations of CCL12 (MCP-5) in mouse macrophage supernatants at different time points. Notes: $*$ Indicates a significant difference from the negative control in the same times. $* \mathrm{P}<0.05$, ** $\mathrm{P}<0.01, * * * \mathrm{P}<0.001 \bullet$ Indicate a significant differences from the $10 \mu \mathrm{g} / \mathrm{ml} \mathrm{rBmpA}$ control group in the same times. $\bullet \mathrm{P}<0.05, \bullet \bullet \mathrm{P}<0.01, \bullet \bullet P<0.001^{\wedge}$ Indicates a significant difference when compared with $20 \mu \mathrm{g} / \mathrm{ml} \mathrm{rBmpA}$ group at $12 \mathrm{~h}$ time point. ${ }^{\Delta} \mathrm{P}<0.05,{ }^{\Delta \Delta} \mathrm{P}<0.01,{ }^{\Delta \Delta \Delta} \mathrm{P}$ $<0.001$

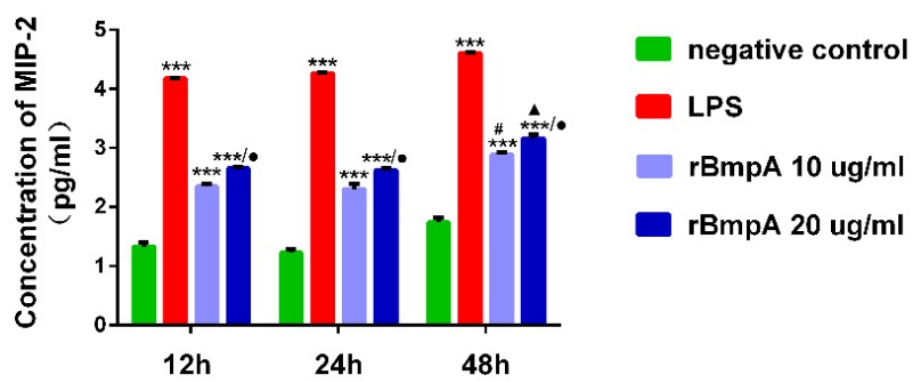

Figure 4. The concentrations of CXCL2 (MIP-2) in mouse macrophage supernatants at different time points. Notes: $*$ Indicates a significant difference from the negative control in the same times. $* \mathrm{P}<0.05$, ** $\mathrm{P}<0.01$, *** $\mathrm{P}<0.001$ Indicate a significant differences from the $10 \mu \mathrm{g} / \mathrm{ml} \mathrm{rBmpA}$ control group in the same times. $\bullet \mathrm{P}<0.05, \bullet \bullet \mathrm{P}<0.01, \bullet \bullet \bullet \mathrm{P}<0.001$ \# Indicates a significant difference when compared with $10 \mu \mathrm{g} / \mathrm{ml} \mathrm{rBmpA}$ group at $12 \mathrm{~h}$ time point. \# $\mathrm{P}<0.05$, \# \# $\mathrm{P}<0.01$, \# \# \# $\mathrm{P}<0.001^{\wedge}$ Indicates a significant difference when compared with $20 \mu \mathrm{g} / \mathrm{ml} \mathrm{rBmpA}$ group at $12 \mathrm{~h}$ time point. ${ }^{\Delta} \mathrm{P}<0.05, \Delta \mathbf{\Delta}<0.01, \Delta \Delta \Delta \mathrm{P}<0.001$ macrophage cells to secrete chemokines, the murine macrophage cell line RAW264.7 was incubated with BmpA or LPS, and the levels of chemokines were measured in culture supernatants. LPS acts as the positive control of this experiment, and as the quality control standard of this experiment, its concentration was $1 \mathrm{ug} / \mathrm{ml}[19,23-25]$. A study reported that B.burgdorferi directly stimulated CD14+ monocytes to secrete CCL4, a chemoattractant for monocytes and some T cells [26]. In addition, Strle et al. demonstrated that $B$. burgdorferi induced macrophages directly to secrete CXCL8, a neutrophil chemoattractant, and CCL3, a chemoattractant for monocytes, and natural killer (NK) and T cells [27]. These chemokines appear to be important for the innate immune responses to $B$. burgdorferi [28].

In this study, using chemokine array, we demonstrated that rBmpA stimulated mouse macrophage RAW264.7 cells to overexpress the chemokines MCP-5 and MIP-2, mRNA expression and protein secretion, found that association between these chemokines and rBmpA concentration were positive related. The chemokine MCP-5(CCL12), which is derived from macrophages, mast cells, fibroblasts, and endothelial cells and has a chemotactic effect on monocytes. T lymphocytes and NK cells that belong to the CC type chemokine family can induce granulocytes to release biologically active agents. A large number of experimental studies have shown that CC chemokines have different degrees of expression in inflammatory-related diseases such as rheumatoid arthritis, acute pancreatitis, and autoimmune diseases [29]. The chemokine MIP-2 (CXCL2) belongs to the CXC type of chemokines and can attract neutrophil aggregation at the inflammatory tissue site. Furthermore, MIP-2 is also one of the chemokines that are closely associated with inflammatory diseases such as acute pancreatitis [29]. Since Lyme arthritis shows pathological changes consisting of synovial hyperplasia, vascular dilatation, and mononuclear cell infiltration, the chemokines MCP-5 and MIP-2 appear to be responsible for promoting neutrophil, monocyte, and other inflammatory cell aggregation at the infection site; therefore, combined with the characteristics of Lyme arthritis and reference antibody chip detection results and in order to further explore the action mechanism of the chemokines in rBmpA induced Lyme arthritis, we selected the MCP-5/CCL12 and MIP-2/CXCL2 to do a further study. The mechanism of 
rBmpA-induced Lyme arthritis was further studied from the gene expression and protein secretion levels.

The mRNA levels of the two chemokines were positively correlated with $\mathrm{rBmpA}$ concentrations as determined by RT-PCR. However, the RT-PCR results showed MCP-5 and MIP-2 gene expression levels in macrophages were not significantly correlated with the time of action of rBmpA; this may be due to rBmpA 'smore predominant promotion of the secretion role in RAW264.7 cells. In addition, it may also be shorter with the mRNA half-life and chemokines in early inflammation of the role of more significant expression of a certain relationship.

The two chemokine levels measured by ELISA showed the same trend as the results of antibody microarray. The two chemokines were significantly increased in cell culture supernatants when macrophages were stimulated by $\mathrm{rBmpA}$; this finding further indicated that $\mathrm{rBmpA}$ may be related to the mechanism of Lyme arthritis but also showed the chemokines may be closely related to Lyme arthritis. It was proven that $\mathrm{rBmpA}$ could stimulate the secretion of chemokines MCP-5 and MIP-2 in RAW264.7 cells. In summary, we found that the levels of chemokines MCP-5/CCL12 and MIP-2/CXCL2 in mouse macrophage cells were up-regulated by rBmpA in a concentration and time-dependent manner.

\section{Conclusions}

Our results showed that the expression levels of the two chemokines in the mouse macrophage RAW264.7 cells were significantly increased after rBmpA stimulation, and the chemokines secreted from BmpA stimulation appear to be closely related to Lyme arthritis.

\section{Acknowledgments}

Yunnan Province Key Laboratory for Tropical Infectious Diseases in Universities, Kunming, China, Yunnan Province Integrative Innovation Center for Public Health, Diseases Prevention and Control, Kunming Medical University, Kunming, China, Yunnan Demonstration Base of International Science and Technology Cooperation for Tropical Diseases, Kunming, China supported this study. We would like to acknowledge the helpful comments from the reviewers.

\section{Funding}

This work was supported by National Natural Science Foundation of China grants (No. 81560596, 31560051), and Natural Foundation of Yunnan Province grants (2017FE467-001), but funding institutions have no role in the study design or review of the manuscript.

\section{Competing Interests}

The authors have declared that no competing interest exists.

\section{References}

1. Beard CB, Hu LT, Hinckley AF, Mead PS. Lyme Disease. Curr Epidemiol Rep. 2016;3(3):1-7.

2. Steere AC. Lyme disease. Trans Am Acad Insur Med. 2001;76(2):586-96.

3. Grygorczuk S, Pancewicz S, Zajkowska J, Kondrusik M, Świerzbińska R, Hermanowska-Szpakowicz T. Concentrations of Macrophage Inflammatory Proteins MIP-1 $\alpha$ and MIP-1 $\beta$ and Interleukin 8 (IL-8) in Lyme Borreliosis. Infection. 2004;32(6):350-5.

4. Gueraudearellano M, Alroy J, Huber BT. Beta2 integrins control the severity of murine Lyme carditis. Infect Immun. 2005;73(6):3242-50.

5. Steere AC, Strle F, Wormser GP, Hu LT, Branda JA, Hovius JW, et al. Lyme borreliosis. Nat Rev Dis Primers. 2016;2:16090.

6. Moore A, Nelson C, Molins C, Mead P, Schriefer M. Current Guidelines, Common Clinical Pitfalls, and Future Directions for Laboratory Diagnosis of Lyme Disease, United States. Emerg Infect Dis. 2016;22(7):1169-77.

7. Puius YA, Kalish RA. Lyme arthritis: pathogenesis, clinical presentation, and management. Infect Dis Clin North Am. 2008;22(2):289-300.

8. Hu L. Lyme arthritis. Infect Dis Clin North Am. 2005;19(4):947-61.

9. Dennis VA, Dixit S, O'Brien SM, Alvarez X, Pahar B, Philipp MT. Live Borrelia burgdorferi spirochetes elicit inflammatory mediators from human monocytes via the Toll-like receptor signaling pathway. Infect Immun. 2009;77(3):1238-45.

10. Bryksin AV, Godfrey HP, Carbonaro CA, Wormser GP, Aguerorosenfeld ME, Cabello FC. Borrelia burgdorferi BmpA, BmpB, and BmpD Proteins Are Expressed in Human Infection and Contribute to P39 Immunoblot Reactivity in Patients with Lyme Disease. Clin Diagn Lab Immunol. 2005;12(8):935-40.

11. Bryksin AV, Tomova A, Godfrey HP, Cabello FC. BmpA is a surface-exposed outer-membrane protein of Borrelia burgdorferi. FEMS Microbiol Lett. 2010;309(1):77-83.

12. Van Solingen RM, Evans J. Lyme disease. Curr Opin Rheumatol. 2001;13(4):293-9.

13. Steere AC, Duray PH, Butcher EC. Spirochetal antigens and lymphoid cell surface markers in Lyme synovitis. Comparison with rheumatoid synovium and tonsillar lymphoid tissue. Arthritis Rheum.1988;31(4):487-95.

14. Bryant VL, Slade CA. Chemokines, their receptors and human disease: the good, the bad and the itchy. Immunol Cell Biol. 2015;93(4):364-71.

15. Brown CR, Blaho VA, Loiacono CM. Susceptibility to experimental Lyme arthritis correlates with $\mathrm{KC}$ and monocyte chemoattractant protein-1 production in joints and requires neutrophil recruitment via CXCR2. J Immunol. 2003;171(2):893-901.

16. X Wang, Y Ma, A Yoder, H Crandall, JF Zachary, RS Fujinami, et al. T cell infiltration is associated with increased Lyme arthritis in TLR2-/- mice. FEMS Immunol Med Microbiol. 2008;52(1):124-33.

17. Strle K, Shin JJ, Glickstein LJ, Steere AC. Association of a Toll-like receptor 1 polymorphism with heightened Th1 inflammatory responses and antibiotic-refractory Lyme arthritis. Arthritis Rheum. 2012;64(5):1497-507.

18. Shin JJ, Strle K, Glickstein LJ, Luster AD, Steere AC. Borrelia burgdorferi stimulation of chemokine secretion by cells of monocyte lineage in patients with Lyme arthritis. Arthritis Res Ther. 2010;12(5):R168.

19. Yang X, Izadi H, Coleman AS, Wang P, Ma Y, Fikrig E ,et al. Borrelia burgdorferi lipoprotein $\mathrm{BmpA}$ activates pro-inflammatory responses in human synovial cells through a protein moiety. Microbes Infect. 2008;10(12):1300-8

20. Pal U, Wang P, Bao F, Yang X, Samanta S, Schoen R, et al. Borrelia burgdorferi basic membrane proteins A and B participate in the genesis of Lyme arthritis. J Exp Med. 2008; 205(1):133-41.

21. Steere AC, Glickstein L. Elucidation of Lyme arthritis. Nat Rev Immunol. 2004; 4(2):143-52.

22. Verma A, Brissette CA, Bowman A, Stevenson B. Borrelia burgdorferi BmpA is a laminin-binding protein. Infect Immun. 2009;77(11):4940-46.

23. Park EK, Shin YW, Lee HU, Kim SS, Lee YC, Lee BY, et al. Inhibitory effect of ginsenoside $\mathrm{Rb} 1$ and compound $\mathrm{K}$ on $\mathrm{NO}$ and prostaglandin $\mathrm{E} 2$ biosyntheses of RAW264.7 cells induced by lipopolysaccharide. Biol Pharm Bull. 2005;28(4):652-6.

24. Sohn KH, Jo MJ, Cho WJ, Lee JR, Cho IJ, Kim SC ,et al. Bojesodok-eum, a Herbal Prescription, Ameliorates Acute Inflammation in Association with the Inhibition of NF-kB-Mediated Nitric Oxide and ProInflammatory Cytokine Production. Evid Based Complement Alternat Med. 2012; 2012:457370.

25. Zhao H, Liu A, Cui Y, Liang Z, Li B, Bao F. Borrelia burgdorferi basic membrane protein A could induce chemokine production in murine microglia cell line BV2. Microb Pathog. 2017;111:174-81.

26. Viola A, Luster AD. Chemokines and Their Receptors: Drug Targets in Immunity and Inflammation. Annu Rev Pharmacol. 2008;48(1): 171-97. 
27. Strle K, Steere AC. Borrelia burgdorferi stimulates macrophages to secrete higher levels of cytokines and chemokines than Borrelia afzelii or Borrelia garinii. J Infect Dis. 2009; 200(12):1936-43.

28. Shin JJ, Glickstein LJ, Steere AC. High levels of inflammatory chemokines and cytokines in joint fluid and synovial tissue throughout the course of antibiotic-refractory lyme arthritis. Arthrit Rheumat. 2007;56(4):1325-35.

29. Christopherson K 2nd, Hromas R. Chemokine regulation of normal and pathologic immune responses. Stem Cells. 2001;19(5):388-96 